\title{
The Use of Artificial Neural Networks to Solve the "Make or Buy"
} Problem

\author{
${ }^{1}$ II'nur I. Farkhoutdinov, ${ }^{2}$ Aleksey G. Isavnin \\ ${ }^{1-2}$ Kazan Federal University \\ Email: ilnour1986@inbox.ru
}

Received: 23 ${ }^{\text {rd }}$ July 2019, Accepted: $10^{\text {th }}$ August 2019, Published: $31^{\text {st }}$ August 2019

\begin{abstract}
Currently, the use of sourcing models is a very popular and promising tool for restructuring large industrial enterprises and optimizing companies in the world, but the experience of both domestic and foreign enterprises shows that not all sourcing has a positive effect on business performance, in particular, each model sourcing has its advantages and disadvantages, which, of course, must be considered. In this regard, in the scientific and practical literature there are a sufficient number of various tools and methodological approaches, one way or another to identify potential difficulties, however, these approaches and tools are not universal for all possible situations, especially since new (unknown) may arise in practice features of models. On the other hand, when solving economic problems, technologies come from other disciplines that can significantly expand the capabilities of existing management tools, such technologies include artificial neural networks. In this regard, it seems appropriate to study aimed at checking the applicability of artificial neural networks for solving certain problems within the framework of sourcing economics.

Outsourcing matrix of Isavnin A.G., Farkhoutdinov I.I. and standard model of artificial neuron were applied.

The applicability of artificial neural networks to solve economic problems in the framework of sourcing is proved.

The results of this work can serve as the basis for the formation of tools to assess the feasibility of using sourcing models through the construction of artificial neural networks.
\end{abstract}

\section{Keywords}

Outsourcing, Insourcing, "Make or Buy", Artificial Neural Networks.

\section{Introduction}

The purpose of this paper is to test the applicability of artificial neural networks for solving economic problems in sourcing, in particular, for solving the "make or buy" problem.

"Make or Buy" Problem

The task "make or buy" is central to the assessment of the feasibility of using sourcing models and, despite the fact that it characterizes the polarity in the decision-making process, in particular, the company's management weighs the possibilities of developing its own production with the possibilities of using third-party suppliers based on solving this problem, new methodological approaches arise, allowing to take into account other sourcing models, for example, such as varieties of sourcing models, hybrid sourcing models and prob. The authors in previously published papers supplemented the "make or buy" task with a hybrid model of cosourcing, and thereby defined a new task - "make and / or buy" $[1,2]$; however, in this paper, as a platform for testing the applicability of artificial neural networks for solving problems within the framework of sourcing economics, we use the classic "make or buy" problem and the most common method of solving it - the outsourcing matrix.

To date, in domestic and foreign scientific and practical literature presents a large number of different outsourcing matrices, briefly consider some of them.

1. Matrix Outsourcing Kurbanov A.Kh.

The outsourcing matrix Kurbanov A.Kh. based on the use of such decision-making factors as "the level of system efficiency" and "the index of expediency of outsourcing / insourcing" [3].

2. Matrix of Outsourcing Moiseeva N.K., Malyutina O.N. and Moskvina I.A.

Matrix outsourcing Moiseeva N.K., Malyutina O.N. and Moskvina I.A. based on the use of such decision-making factors as "strategic importance" and "level of competence" [4].

3. Matrix Outsourcing K. Vitachek and M. Ledyard

The outsourcing matrix of K. Vitachek and M. Ledyard is based on the use of such decision-making factors as "potential value for an organization" and "organizational expertise" [5].

4. Matrix of Outsourcing R. McIvor, P. Humphreis, E. Wall and A. McKittrick

The outsourcing matrix of R. McIvor, P. Humphreis, E. Wall and A. McKittrick is based on the use of such decisionmaking factors as "relative feasibility" and "importance of the process to competitive advantage" [6].

5. Matrix Outsourcing Isavnin A.G. and Farkhoutdinov I.I.

This matrix was proposed by the authors in earlier publications, and it is based on the use of such decision-making factors as "strategic importance" and "profitability".

About Artificial Neural Networks

Today, artificial neural networks are one of the most demanded information processing tools that are widely used to implement innovative technological solutions in the field of technical pattern recognition, in managing complex 
systems, for processing voice messages, and so on, however, despite the high demand and growing popularity , which, inter alia, is characterized by the application of this mathematical model in economics, finance and healthcare, artificial neural networks yes clearly known to the academic and professional communities, in particular, the first formal model of an artificial neuron was presented as early as 1943 by American scientists Warren McCulloch and Walter Pitts [7], and the periods of rapid development of the theory of neural networks are the $60 \mathrm{~s}$ and $80 \mathrm{~s}$ of the last century , which, first of all, are associated with such names as Frank Rosenblatt, who published a book in 1962 with the theory of dynamic neural systems for modeling brain activity [8], and John Hopfield, whose work was published in 1982 became the starting point for the rapid development of the theory of neural networks [9].The areas of application of neural network technologies are very diverse - this, as noted above, is pattern recognition, stock price and exchange rate forecasting, license plate recognition and personal identification, and many others; and at the moment there are a number of companies on the market that specialize in developing application software products, including those that allow working with various types of artificial neural networks [10]. Next, we consider some examples of the use of neural network technologies in the economy.

1. Modeling Shopping Center Segmentation.

In the scientific work Polupanov D.V. and Khairullina N.A. investigates the problem of structuring the market of shopping centers on the example of Ufa; in particular, the authors have proposed methods for segmentation of shopping centers on the basis of quantitative characteristics that have the greatest impact on the popularity and attendance of shopping centers. As a tool for solving the task, a neural network learning algorithm "without a teacher" was used Kohonen self-organizing cards. As a result of modeling, the authors obtained stable estimates, which make it possible to draw conclusions and practical recommendations for making decisions on the further development of shopping centers and increasing market transparency [11].

\section{Identification of Potential Customers of the Bank, Delaying Payments on Loans.}

Angoss based on artificial neural networks developed the KnowledgeSeeker software for credit organizations, which allows to find out which clients in the future will be likely to delay payments on loans. This software was applied by Canadian bank CIBC, as a result of which it turned out that in the future problems with payments would arise for those bank customers who, against the background of regular payments, sometimes allegedly forgot to pay, and this forgetfulness was associated with serious financial difficulties [12].

3. Track Suspicious Transactions.

The American Bank Chemical Bank uses a software product developed by Neural Data based on artificial neural networks that processes transactions on the currency exchanges of several countries in order to track suspicious transactions [13].

HNC has developed a Falcon software product based on a neural network that allows you to detect and prevent suspicious transactions on stolen cards in real time. Large banks that have applied this product, significantly reduced the damage from such crimes [14].

4. Forecasting the Effectiveness of Investments.

In scientific work Khrustalev E.Yu. and Shramko O.G. The proposed method based on the use of artificial neural networks, which, with a limited number of initial indicators characterizing the economic activity of the region, allows to obtain fairly accurate estimates of the effectiveness of the investment policy in relation to each subject of the Russian Federation. The proposed method allows the authors to determine the most appropriate direction of investment for the socio-economic development of regions [15].

5. Analysis of the Dynamics of Innovative Activity of the Regions.

In the scientific work Perova V.I. and Zaitseva K.V. on the basis of neural network modeling, a study was conducted of indicators characterizing the dynamics of innovation activities of the regions of the Russian Federation for 2012-2015. As a result of the analysis, innovatively underdeveloped regions of the country were identified that need government support to stimulate innovation processes [16].

Next, we consider the basic concept of the theory of neural networks - a formal neuron, in particular, the standard model of a neuron and on the basis of this model we will demonstrate the solution of the "make or buy" problem.

\section{Methods}

Standard Neuron Model

The standard model of a neuron along with a pade-neuron, a neuron with a quadratic adder, a neuron with a coincidence counter [17], an neuron of the adaline type [18], and other models is a type of formal neuron and is the usual McCulloch-Pitts model proposed as noted above, in 1943, which simulates the work of a biological neuron and is the simplest element of an artificial neural network. The block diagram of a standard neuron is shown in Figure 1, and the mathematical model is:

$y=F(S)=F\left(\sum_{i=1}^{n} x_{i} w_{i}\right)$,

$y$ - neuron output; $F(S)$ - activation function; $w_{i}$ - weight of the i-th entry; $x_{i}-\mathrm{i}$-th input signal; $i$ - neuron entry number; $n$ - number of inputs.

In general, the work of a standard neuron is as follows. Each i-th input of the neuron receives signals $x_{i}$ from other neurons. Each $x_{i}$ signal is multiplied by the synaptic coefficient $w_{i}$. Further, the results of these multiplications are algebraically added and the resulting sum is fed to the functional transformation block $F(S)$. 


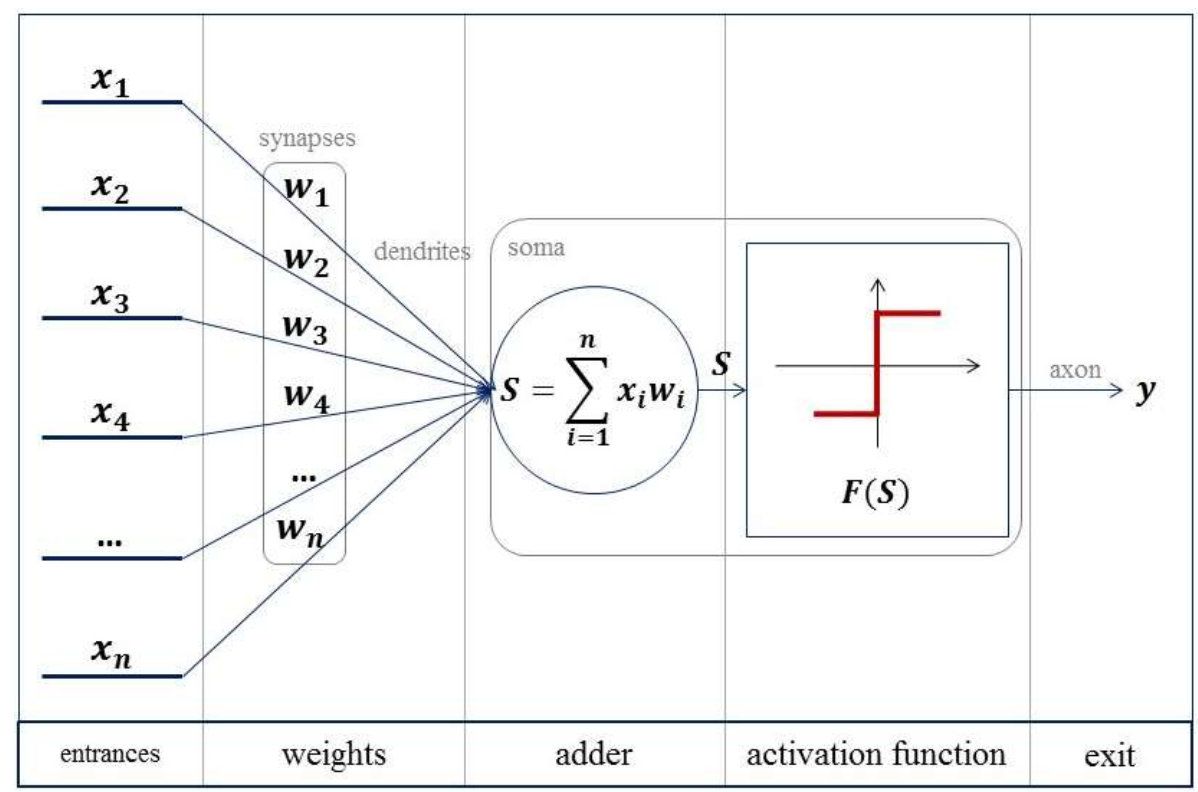

Figure 1: Standard Neuron Model

Due to the fact that the testing of the applicability of neural networks for solving the "make or buy" task is carried out on the basis of an artificial neuron, the presented standard model does not contain the variable "initial state of the neuron".

\section{Results and Discussion}

As noted above, testing the applicability of neural networks for solving the "make or buy" task is carried out on the basis of an artificial neuron, in particular, by transferring the outsourcing matrix to Isavnin A.G. and Farkhoutdinov I.I. to the standard model of a formal neuron, where the decision factor "strategic importance" corresponds to the input signal $x_{1}$, and the factor "profitability" $x_{2}$, and the activation function is a threshold function that produces two possible variants of the output signal - outsourcing (see figure 2 ), that is, described as follows:

$F(S)=\left\{\begin{array}{c}\text { outsourcing, if } S<T ; \\ \text { insourcing, if } S \geq T,\end{array}\right.$

$T$ - neuron threshold.

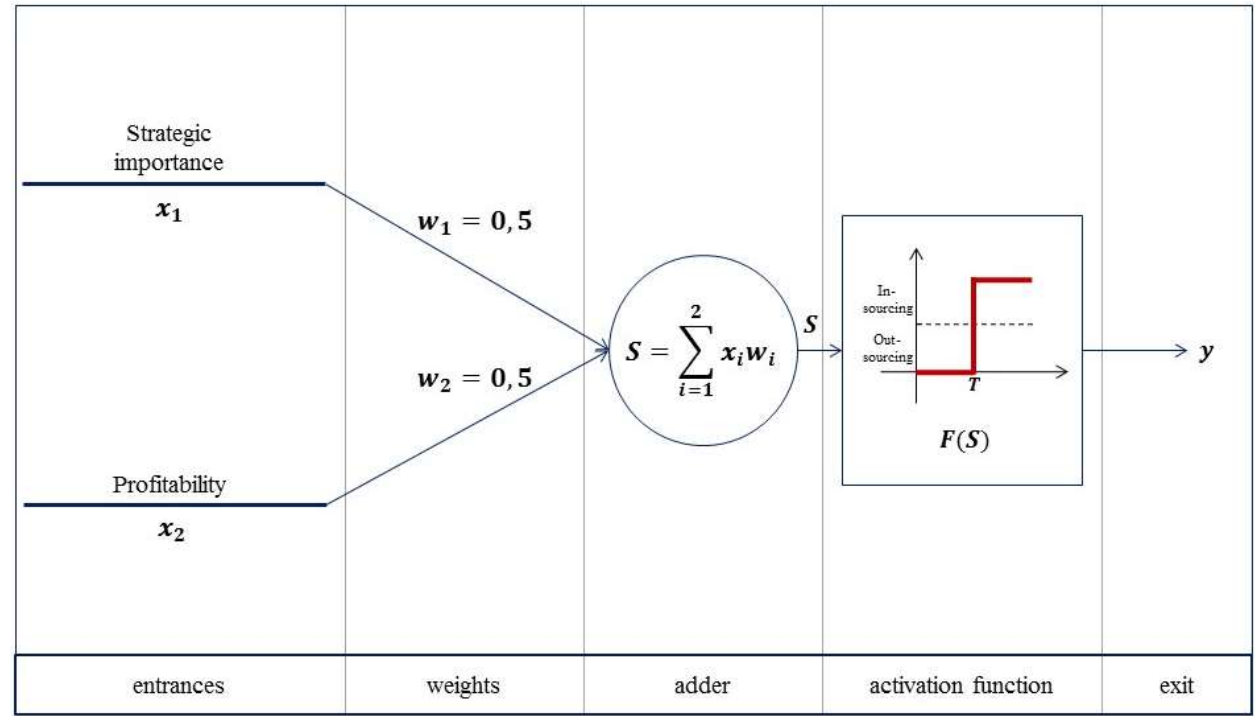

Figure 2: The Outsourcing Matrix in the Context of an Artificial Neuron

Due to the fact that in the matrix of outsourcing Isavnin A.G. and Farkhoutdinov I.I. the decision factors "strategic significance" and "profitability" are equivalent, the weights of the input signals $x_{1}$ and $x_{2}$ are equal to each other and the value 0,5 , that is, $w_{1}=w_{2}=0,5$.

The mathematical model of an artificial neuron that solves the "make or buy" problem is: $y=F(S)=F\left(x_{1} w_{1}+x_{2} w_{2}\right)$, 
Based on the proposed model, as well as the fact that an artificial neuron can receive more than 2 input signals, therefore, this advantage eliminates the main disadvantage of the outsourcing matrix - two-factor [19], we can conclude that the use of artificial neural networks to solve the "make or buy" is a very promising direction for the development of tools for assessing the feasibility of using sourcing models.

\section{Summary}

The next step is to build a full-fledged neural network based on the proposed primitive model, which, at a minimum, should cover the following aspects.

1. Classification.

Obviously, the input signals of an artificial neural network solving the "make or buy" task should not be the decisionmaking factors themselves, but the criteria that form these factors, for example, as noted in a previously published work, the criteria that form the "strategic significance" factor may be "significance for the brand", "prospects for the future", "market of outsourcers" and others [1], and the decision factor "profitability" can be renamed into "economic significance", formed, for example, by such criteria as "marginal I am profitability, "' the share of net profit in marginal profitability, "" the degressiveness of the purchase price of the component, "and so on. In this case, the neural network will be the task of classification, the meaning of which is to correctly assign the input signal to one of the decision factors.

\section{Clustering.}

In this case, clustering refers to the formation of new decision-making factors that were not previously identified in the learning process or not specified by the developer.

3. Activation Function.

In the primitive model, which solves the "make or buy" problem, a threshold activation function was applied, which produced two possible output signal variants - insourcing or outsourcing. This is obviously not enough when building an artificial neural network, since, firstly, the scientific and practical literature presents a large number of varieties of both insourcing and outsourcing, which can differ significantly from each other, for example, speaking of restructuring outsourcing, such models as "minimal outsourcing", "effective outsourcing" and "radical outsourcing" [20], and, moreover, today the classification of forms and types of sourcing is not well-established and final [1], but the second is to exist other models in addition to insourcing and outsourcing, such as hybrid models - co-sourcing and sourcing's maneuver model [21]. Therefore, the actual issue is the use of such activation functions in neural networks, which would include several sourcing models and / or model varieties.

\section{Learning Neural Network.}

The essence of this aspect is to develop an artificial neural network, to train this mathematical model in the reference environment and, thus, competently learn from the successful experience of domestic or foreign companies.

\section{Conclusions}

The results of this work demonstrate the possibility of using artificial neural networks to solve economic problems, in particular, the problem of "make or buy", and building tools to assess the feasibility of using sourcing models based on intelligent mathematical methods is a promising direction in the development of theory of modeling the use of resources.

\section{Acknowledgements}

The work is performed according to the Russian Government Program of Competitive Growth of Kazan Federal University.

\section{References}

[1] Isavnin A.G., Farkhoutdinov I.I. Features of the application of production outsourcing at a Russian automotive enterprise // LAP LAMBERT Academic Publishing, AV Akademikerverlag GmbH \& Co. KG. KG, 2013, Saarbruecken, Germany, ISBN 978-3-659-42197-6, 188 pages.

[2] Farkhoutdinov I. Ilnour and Isavnin G. Alexey, 2016. Justification of Expediency of Application of Industrial Cosourcing at Industrial Enterprises. International Business Management, 10: 4580-4587.

[3] Kurbanov A.Kh. Methods of assessing the feasibility of using outsourcing // Modern problems of science and education. - 2012. - № 1. URL: http://www.science-education.ru/pdf/2012/1/138.pdf

[4] Moiseeva N.K., Malyutin O.N, Moskvin I.A. [Outsourcing in development of business partnership], ed. Moiseeva N.K. - M.: Finance and statistics; INFRA-M, 2010. - pp. 240.

[5] Vitasek Kate. Vested Outsourcing: Five Rules That Will Transform Outsourcing. 2nd ed. New York [u.a.]: Palgrave Macmillan, 2013

[6] Ronan McIvor, Paul K. Humphreys, Anthony p. Wall, Alan McKittrick. A study of performance measurement in the outsourcing decision. Research executive summaries series, Vol. 4, Issue 3. pp. 1-13. Available at: http://www.cimaglobal.com/documents/importeddocuments/cid_ressum_a_study_of_performance_measurement in_the_outsourcing_decision_dec08.pdf

[7] McCulloch W.S., Pitts W.H. A logical calculus of ideas immanent in nervous activity // Bull. Math. Biophysics, 1943. - Vol. 5. - Pp. 436-440. 
[8] Rosenblatt F. Principle of neurodynamics. - N.Y.: Spartan, 1992.

[9] Hopfield J. Neural networks and physical systems with emergent collective computational abilities // Proc. National Academy of Science USA, 1982. - Vol. 70. - Pp. 2554-2558.

[10] Bogoslavsky S.N. Scope of artificial neural networks and their development prospects // Scientific Journal of Kuban State Agrarian University, №27 (3), 2007.

[11] Polupanov D.V., Khairullina N.A. Intellectual modeling of shopping center segmentation based on Kohonen self-organizing maps // Internet magazine "Naukovedenie", issue 1, January-February 2014.

[12] Pisarenko I. Neural network technologies in security // Information security. 2009, №4.

[13] Kondrashova A.S. The use of neural networks for forecasting in the financial markets // Journal "Alley of Science", volume 3, number 9, 2017, pp. 280-283.

[14] Kastornova V.A., Mozhaeva M.G. Artificial neural networks as modern means of informatization // Information environment of education and science. - 2012. - №7. - p. 1-17.

[15] Khrustalev E.Y., Shramko O.G. Using the method of neural networks to predict the effectiveness of investments // Journal "Economic analysis: theory and practice", №8, 2017.

[16] Perova V.I., Zaitseva K.V. Study of the dynamics of innovation activities of the regions of Russia with the use of neural network modeling // Journal "Economic Analysis: Theory and Practice", №5, 2017.

[17] Neural networks on a personal computer / A.N. Gorban, D.A. Rossiev. Novosibirsk: Science, Siberian Publishing Company of the Russian Academy of Sciences, 1996

[18] Widrow B., Hoff M. Adaptive switching circuits // Proc. IRE WESCON Convention Record, 1960. - Pp. 107115.

[19] Firsova S.A. Tools for the assessment of outsourcing non-core business functions. 2010. URL:http://new.mrconsulting.ru/lib/articles/?id=3

[20] I.I. Farkhoutdinov, A.G. Isavnin Restructuring of Russian enterprises on basis of industrial outsourcing // Astra Salvensis, No 2/2017.

[21] I.I. Farkhoutdinov, A.G. Isavnin Sourcing's Maneuver as Tool for Effective Restructuring of Industrial Enterprise // International Journal of Engineering \& Technology, 2018 